\title{
IMPROVEMENT OF THE STRUCTURAL, ELECTRICAL AND MAGNETIC PROPERTIES OF CALCIUM W-TYPE HEXAFERRITE NANO SIZED POWDERS USING CO-PRECIPITATION METHOD
}

\author{
C. L. Khobaragade ${ }^{1}$, S. B. Deshpande ${ }^{2}$, S. V. Soni ${ }^{3}$ and K. G. Rewatkar ${ }^{4}$ \\ ${ }_{1,2}$ Govindrao Wanjari College of Engg. \& Technology, Nagpur, India. \\ ${ }^{3}$ Yashwantrao Chavan College of Engg. Nagpur, India. \\ ${ }^{4}$ Dr. Ambedkar College, Deeksha Bhoomi, Nagpur, India.
}

\begin{abstract}
:
In the present investigation, the samples with chemical composition $\mathrm{CaSr}_{2}(\mathrm{MnZn})_{\mathrm{x} / 2} \mathrm{Fe}_{16-\mathrm{x}} \mathrm{O}_{27}$ with $(\mathrm{x}=0$ to 1$)$ have been synthesized using perfect stoichiometric proportions of nitrates by chemical co-precipitation technique. The pellets of $15 \mathrm{~mm}$ diameter were prepared and sintered at $1000^{\circ} \mathrm{C}$ for $4 \mathrm{hr}$ and characterized by using XRD, SEM, electrical and magnetic properties. XRD studies of the samples showed hexagonal W-type structure with unit cell

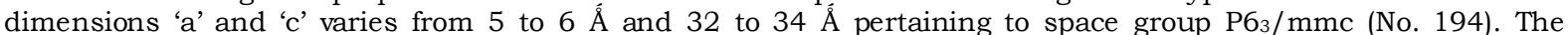
variation in the values of lattice parameter has to be recorded with increase in $\mathrm{Mn}-\mathrm{Zn}$ conc. The magnetic properties of prepared W-type Ca-hexaferrite powder were investigated by VSM studies at 20,000 G magnetic field. The transition temperature and activation energies have been investigated from electrical behaviour of the samples.
\end{abstract}

Keywords: XRD, SEM, VSM, Electrical and Magnetic properties, Curie temperature.

\section{Introduction:}

Hexaferrites have been the subject of intensive studies due to an appealing combination of good magnetic properties and low cost. This large family of oxides with hexagonal crystal structure contains ferrimagnetic compounds with easy axis of magnetization (e.g. M-type ferrites) and easy plane of magnetization (e.g. Y-type ferrites). Hence, hexaferrites have been widely adopted in two distinct fields: permanent magnets and microwave technology components [1]. On the other hand, W-type ferrites $\mathrm{CaM}_{2} \mathrm{Fe}_{16} \mathrm{O}_{27}(\mathrm{M}=$ $\mathrm{Mg}, \mathrm{Mn}, \mathrm{Fe}, \mathrm{Sr}, \mathrm{Co}, \mathrm{Ni}, \mathrm{Cu}, \mathrm{Zn}$ ) can undergo spin reorientation transitions (SRT) between different anisotropy configurations (easy plane $\leftrightarrow$ easy cone $\leftrightarrow$ easy axis) induced by change of temperature or applied magnetic field [2-9]. The transition temperature can be tuned by modifying the chemical composition (substitution of bivalent metal M). Moreover, some SRT are expected to be of the first order, which suggests a potential application of W-type ferrites in room temperature magnetic refrigeration [10].

Conventional ceramic method of hexaferrite synthesis is efficient, but requires elevated temperatures for solid state reaction to occur between premixed powders. Alternative production routes (aerosol pyrolysis, chemical co-precipitation, glass crystallization, hydrothermal synthesis, etc.) are intended to improve mixing of initial components down to atomic level and thereby to facilitate diffusion. In particular, a chemical co-precipitation technique enables to obtain sufficiently homogeneous precursors for low temperature synthesis of nanosized ferrites. However, hexagonal ferrites with complex layered crystal structures still require relatively high temperatures to form because of thermodynamic stability conditions. Trying to avoid rapid growth of grains, we have used this soft-chemistry approach for production of W-type ferrites. An important goal was to determine the heat treatment regimes ensuring complete transformation of a precursor into the smallest particles of single $\mathrm{W}$-phase. In this paper the results of structural, electrical, magnetic and mechanical characterization $\mathrm{CaSr}_{2}(\mathrm{MnZn})_{\mathrm{x} / 2} \mathrm{Fe}_{16-\mathrm{x}} \mathrm{O}_{27}$ of powders are presented.

\section{Experimental:}

Hexaferrite powders have been prepared by a chemical co-precipitation method [11]. The A. R. grade nitrates have been used as starting material. Stoichiometric proportion of calcium nitrate, ferric nitrate, zinc nitrate, manganese nitrate, strontium nitrate $(99.9 \%)$ etc. have been dissolved one by one in $100 \mathrm{ml}$ of de-ionized water. Ammonia solutions (30\%) have been added slowly in the mixture to adjust $\mathrm{pH}$ of 8 . The mixed solutions have been stirred for $2 \mathrm{hr}$ and will be kept at room temperature for $24 \mathrm{hr}$ for aging. The calcium hexaferrites precipitates have been separated in a centrifuge machine at $2500 \mathrm{rpm}$ for 20 minute. The prepared precipitates have been washed in 1:1 mixture of methanol and acetone followed by $100 \%$ deionized water to remove impurities. The 
precipitates have been dried at $100^{\circ} \mathrm{C}$ for $24 \mathrm{hrs}$ and calcinated at $1000^{\circ} \mathrm{C}$ for $4 \mathrm{hrs}$. to obtain $\mathrm{CaSr}_{2}(\mathrm{MnZn})_{\mathrm{x} / 2} \mathrm{Fe}_{16-\mathrm{x}} \mathrm{O}_{27}$ hexaferrite particles [11].

Crystal structure were examined by PA Analytical X'Pert Pro X-ray diffraction (XRD) in $\mathrm{Cu}-\mathrm{Ka}$ radiation with accelerator detector for rapid data acquisition. Magnetization curves were recorded on Lake Shore vibrating sample magnetometer (VSM). The lattice parameters and X-ray densities of the samples have been computed from XRD analysis. The bulk density has been determined by mass and bulk volume of the samples, while porosity for each sample has been calculated separately. Structural analysis has been carried out from SEM and XRD of the studied materials.

\section{Results and Discussion: Structural Analysis:}

The XRD patterns of $\mathrm{Mn}-\mathrm{Zn}$ doped CaM ferrites were (Figure. 1) taken after final sintering at $1000^{\circ} \mathrm{C}$ for $4 \mathrm{hr} \mathrm{CaSr}_{2}(\mathrm{MnZn})_{\times / 2} \mathrm{Fe}_{16}$ ${ }_{\mathrm{x}} \mathrm{O}_{27}$ with ( $\mathrm{x}=0$ to 1 ) and showed the formation of hexaferrite along with some individual

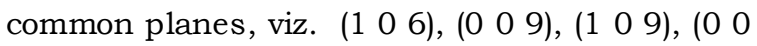
12), (2 0 0), (2 1 1 9 $),\left(\begin{array}{lll}1 & 1 & 17\end{array}\right),\left(\begin{array}{lll}3 & 0 & 1\end{array}\right)$ etc., which carries almost equal intensity. The existence of these common planes in all the compounds is an indication of hexagonal Wferrite, which belongs to the space group $\mathrm{P}_{3} / \mathrm{mmc}$. The lattice parameter ' $\mathrm{a}$ ' and ' $c$ ' for different compositions have been calculated using the values of d-spacing and from Bragg's law by using formula $\frac{1}{d^{2}}=\frac{4\left(h^{2}+k^{2}+k h\right)}{\left(3 a^{2}\right)}+\frac{l^{2}}{c^{2}}$ and compared to the values reported in JCPDC (Joint Committee on Powder Diffraction Standards) cards [12]. The lattice parameter 'a' shows the decreasing trend and 'c' values shows increasing trend with the added impurities this is due to the difference between ionic radii of $\mathrm{Mn}^{+4}(0.60 \AA \hat{)}), \mathrm{Zn}^{+2}(0.74 \AA \bar{A})$, which is slightly less than that of $\mathrm{Fe}^{+3}(0.67 \AA \tilde{A})$.

The W-type hexaferrites contains one additional S-block per formula unit, which leads to the formation of two sites for divalent ions per formula unit (assuming divalent large cations and trivalent small ions). One unit cell of W-type hexaferrite contains 2-formula unit. Stacking sequence is $\mathrm{RSSR}^{*} \mathrm{~S}^{*} \mathrm{~S}^{*}$ and space group is $\mathrm{P} 63 / \mathrm{mmc}$. The crystallographic positions of iron W-type hexaferrites are listed in Table-1 together with orientations of magnetic moments of the sites. These are seven inequivalent small cations sites in W-type. Unit cell of W-type are shown in Figure. 2. One can see that W-type resembles M-type with pair of S-blocks in place of single S-block in M-type. In W-type structure the planes of large cations perpendicular to hexagonal axis are mirror planes.

Direct observations of $\mathrm{W}$-ferrite particles were performed by SEM. Powders calcined at $1000^{\circ} \mathrm{C}$ consist of aggregates of clean and almost hexagonal particles not exceeding 122 $\mathrm{nm}$, as shown in Figure. 2(a). The shape of crystallite reflects their hexagonal crystal structure. The particles have a wide size distribution from $33 \mathrm{~nm}$ to $200 \mathrm{~nm}$ and are mostly hexagonal like. This morphology is observed for $1000^{\circ} \mathrm{C}$ when W-type ferrite is almost single phase [13].

The well-known Scherrer formula [14] has been used to determine the particle size from the line broadening of diffraction profile of the strongest peak. The formula, excluding the effects of the machine broadening to minimize errors, is given below:

$$
\mathrm{D}=\frac{\mathrm{k} \lambda}{\mathrm{b} \cos \theta}
$$

where, $\mathrm{D}=$ average particle size, $\mathrm{k}=$ Scherrer constant $(\mathrm{k}=0.9), \lambda=$ wavelength of radiation (1.54056̊̊), b = peak with at half height (full width half maxima, FWHM) and $\theta$ corresponds to the peak position measured in radians. The measured values were corrected for the effects caused by instrumental broadening. The particle size for the studied samples have been calculated and found in the range of $33.84 \mathrm{~nm}$ to $48.01 \mathrm{~nm}$ shown in table-1. It has been reported that the crystallite size less than $50 \mathrm{~nm}$ is required in obtaining the suitable signal-tonoise ratio in the high density recording media [15]. So these materials can be used for applications in high density recording media in obtaining suitable signal-to-noise ratio.

The X-ray density has been calculated using the relation for hexagonal ferrite [16] given below:

$$
\mathrm{dx}=\frac{2 \mathrm{M}}{\mathrm{N} 0.866 \mathrm{a}^{2} \mathrm{c}}
$$

where, $\mathrm{M}=$ molecular weight of the sample, volume (V) for hexagonal $=0.866 \mathrm{a}^{2} \mathrm{c}, \mathrm{N}=$ Avogadro's number. The X-ray density (dx) depends on the lattice constant and molecular weight of the samples whereas the bulk density (d) of the sample can be calculated from the geometry of the crystals and mass of the samples. Both densities increases with the increase in concentration of $\mathrm{Mn}-\mathrm{Zn}$ as it is inversely proportional to the lattice constants, also the porosity showed decreasing trend with increasing $\mathrm{Mn}-\mathrm{Zn}$ conc., shown in Table-2. This change may be due to the difference in the specific gravity of $\mathrm{Mn}^{+4}\left(7.21 \mathrm{~g} / \mathrm{cm}^{3}\right)$ and $\mathrm{Zn}^{+2}$ $\left(7.133 \mathrm{~g} / \mathrm{cm}^{3}\right)$ as described in CRC book [17] or 
due to the ionic difference between the $\mathrm{Mn}$ and $\mathrm{Zn}$, as reported in the literature [18, 19-21].

Electrical Properties: Electrical conductivity measurements have been studied by plotted graphs between $\log \sigma$ vs inverse temperature which found to be linear with kink to the Curie temperature as shown in Figure. 4(a, b, c, d, e, f). The Curie temperature (Tc) has been found in the range of $473 \mathrm{~K}$ to $498 \mathrm{~K}$ which is shown in Table-3. The activation energy has been found in the range of $0.129 \mathrm{eV}$ to $0.385 \mathrm{eV}$ in ferrimagnetic and $0.342 \mathrm{eV}$ to $0.838 \mathrm{eV}$ in paramagnetic region. In the paramagnetic region, the activation energy is more as compared to the ferrimagnetic region; this is due to the valence exchange interaction between $\mathrm{Fe}^{+3}$ and $\mathrm{Fe}^{+2}$ ions [22] which is shown in Table2 .

Magnetic properties: The magnetic properties of W-type samples have been studied by Vibrating Sample Magnetometer (VSM) in the applied field upto $20 \mathrm{KG}$ at room temperature Figure. 5(a, b).

The B-H curve measurements have been carried out at room temperature. The observed results have been explained on the basis of site distribution. The saturation magnetization (Ms), coercivity (Hc), remanance magnetization (Mr), magnetic moment $\left(\mu_{B}\right)$ and relative permeability $\left(\mu_{r}\right)$ have been calculated for $\mathrm{Mn}-\mathrm{Zn}$ conc. at $\mathrm{x}=$ 0 to 1.0 added in the sample. It is observed that the saturation magnetization varies in the range of $13.97 \mathrm{emu} / \mathrm{g}$ to $40.45 \mathrm{emu} / \mathrm{g}$, coercivity varies in the range of $4918.8 \mathrm{G}$ to $5385.8 \mathrm{G}$, remanance magnetization varies in the range of
$7.64 \mathrm{emu} / \mathrm{g}$ to $22.14 \mathrm{emu} / \mathrm{g}$, magnetic moment varies in the range of 3.8585 to 11.1894 and relative permeability varies in the range of 30.0202 to 86.0133 Table-4.

Figure.5 (a,b) shows the saturation magnetization of W-type $\mathrm{CaF}(40.45 \mathrm{emu} / \mathrm{g})$ is too far away from the theoretically estimated value of $72 \mathrm{emu} / \mathrm{g}$ [23] and the coercivity are found to be $5385 \mathrm{G}$, respectively. It is well known that the coercivity of calcium ferrite depends on many factors, such as chemical composition, particle size, degree of crystallinity, microstructure, magnetic anisotropy, etc. However, recent progress indicate that the coercivity is also strongly influenced by the particle size [24-28], whose variation can also induce the obvious change in

saturation magnetization and magnetic anisotropy, etc. A good saturation magnetization is achieved at annealing temperature $1000^{\circ} \mathrm{C}$ for $4 \mathrm{hr}$, which attributed to the formation of clear and regular hexagonal structure. Moreover, the shape of the hysteresis loop curves confirmed that the calcium ferrite was a hard magnet [29].

Table-1

\begin{tabular}{|l|l|l|}
\hline Block & Coordination & $\begin{array}{l}\text { Orientation of } \\
\text { Moments }\end{array}$ \\
\hline $\mathrm{R}$ & Octahedral & $\downarrow 4 \mathrm{f}_{\mathrm{VI}}$ \\
\hline $\mathrm{R}$ & Bipyramidal & $\uparrow 2 \mathrm{~d}$ \\
\hline $\mathrm{SS}$ & Octahedral & $\uparrow 4 \mathrm{f}_{\mathrm{VI}}$ \\
\hline SS & Tetrahedral & $\downarrow 4 \mathrm{e}, \downarrow 4 \mathrm{f}_{\mathrm{IV}}$ \\
\hline R-SS & Octahedral & $\uparrow 12 \mathrm{k}$ \\
\hline S-S & Octahedral & $\uparrow 6 \mathrm{~g}$ \\
\hline
\end{tabular}

Table-2:

\begin{tabular}{|c|c|c|c|c|c|c|c|}
\hline Sample & $\mathbf{a}(\mathbf{\AA})$ & $\mathbf{c}(\mathbf{A})$ & Volume & $\mathbf{D}(\mathbf{n m})$ & $\mathbf{d x}\left(\mathbf{g} / \mathbf{c m}^{3}\right)$ & $\mathbf{d ~}\left(\mathbf{g} / \mathbf{c m}^{3}\right)$ & $\mathbf{P}$ \\
\hline $\mathrm{CaSr}_{2} \mathrm{Fe}_{16} \mathrm{O}_{27}$ & 5.82 & 33.08 & 1120.88 & 47.67 & 5.27 & 2.95 & 0.44 \\
\hline $\mathrm{CaSr}_{2}(\mathrm{MnZn})_{0.1} \mathrm{Fe}_{15.8} \mathrm{O}_{27}$ & 5.81 & 33.10 & 1117.56 & 33.84 & 5.29 & 3.06 & 0.42 \\
\hline $\mathrm{CaSr}_{2}(\mathrm{MnZn})_{0.2} \mathrm{Fe}_{15.6} \mathrm{O}_{27}$ & 5.79 & 33.18 & 1110.91 & 36.02 & 5.32 & 3.11 & 0.42 \\
\hline $\mathrm{CaSr}_{2}(\mathrm{MnZn})_{0.3} \mathrm{Fe}_{15.4} \mathrm{O}_{27}$ & 5.78 & 33.23 & 1110.34 & 40.18 & 5.33 & 3.20 & 0.40 \\
\hline $\mathrm{CaSr}_{2}(\mathrm{MnZn})_{0.4} \mathrm{Fe}_{15.2} \mathrm{O}_{27}$ & 5.80 & 33.23 & 1116.38 & 48.01 & 5.30 & 3.30 & 0.38 \\
\hline $\mathrm{CaSr}_{2}(\mathrm{MnZn})_{0.5} \mathrm{Fe}_{15} \mathrm{O}_{27}$ & 5.77 & 33.48 & 1116.18 & 41.18 & 5.31 & 3.08 & 0.42 \\
\hline
\end{tabular}

Table-3

\begin{tabular}{|l|l|c|l|}
\hline & \multicolumn{2}{|l|}{$\begin{array}{l}\text { Activation } \\
\text { Energy }\end{array}$} & \multirow{2}{*}{$\begin{array}{l}\text { Tc } \\
\text { Sample }\end{array}$} \\
\cline { 2 - 3 } & $\begin{array}{l}\text { Ferri } \\
\text { (eV) }\end{array}$ & $\begin{array}{c}\text { Para } \\
\text { (eV) }\end{array}$ & \\
\hline $\mathrm{CaSr}_{2} \mathrm{Fe}_{16} \mathrm{O}_{27}$ & 0.318 & 0.569 & 483 \\
\hline $\mathrm{CaSr}_{2}\left(\mathrm{MnZn}_{0.1} \mathrm{Fe}_{15.8} \mathrm{O}_{27}\right.$ & 0.325 & 0.718 & 493 \\
\hline $\mathrm{CaSr}_{2}(\mathrm{MnZn})_{0.2} \mathrm{Fe}_{15.6} \mathrm{O}_{27}$ & 0.385 & 0.838 & 473 \\
\hline $\mathrm{CaSr}_{2}(\mathrm{MnZn})_{0.3} \mathrm{Fe}_{15.4} \mathrm{O}_{27}$ & 0.129 & 0.369 & 483 \\
\hline $\mathrm{CaSr}_{2}(\mathrm{MnZn})_{0.4} \mathrm{Fe}_{15.2} \mathrm{O}_{27}$ & 0.323 & 0.342 & 498 \\
\hline $\mathrm{CaSr}_{2}(\mathrm{MnZn})_{0.5} \mathrm{Fe}_{15} \mathrm{O}_{27}$ & 0.333 & 0.346 & 498 \\
\hline
\end{tabular}


Table-4

\begin{tabular}{|l|l|l|l|l|l|}
\hline Sample & $\begin{array}{l}\text { Hc } \\
\text { (Gauss) }\end{array}$ & $\begin{array}{l}\mathbf{M s} \\
\text { (emu/g) }\end{array}$ & $\begin{array}{l}\text { Mr } \\
\text { (emu/g) }\end{array}$ & 伍 & $\boldsymbol{\mu}_{\mathbf{r}}$ \\
\hline $\mathrm{CaSr}_{2} \mathrm{Fe}_{16} \mathrm{O}_{27}$ & 5217.3 & 28.41 & 15.77 & 7.8380 & 57.7933 \\
\hline $\mathrm{CaSr}_{2}(\mathrm{MnZn})_{0.1} \mathrm{Fe}_{15.8} \mathrm{O}_{27}$ & 5179.1 & 21.66 & 12.29 & 5.9786 & 45.7003 \\
\hline $\mathrm{CaSr}_{2}(\mathrm{MnZn})_{0.2} \mathrm{Fe}_{15.6} \mathrm{O}_{27}$ & 4918.8 & 13.97 & 7.64 & 3.8585 & 30.0202 \\
\hline $\mathrm{CaSr}_{2}(\mathrm{MnZn})_{0.3} \mathrm{Fe}_{15.4} \mathrm{O}_{27}$ & 5124.1 & 20.77 & 11.69 & 5.7398 & 45.8373 \\
\hline $\mathrm{CaSr}_{2}(\mathrm{MnZn})_{0.4} \mathrm{Fe}_{15.2} \mathrm{O}_{27}$ & 5385.8 & 36.35 & 19.79 & 10.0508 & 82.7538 \\
\hline $\mathrm{CaSr}_{2}(\mathrm{MnZn})_{0.5} \mathrm{Fe}_{15} \mathrm{O}_{27}$ & 5210.1 & 40.45 & 22.14 & 11.1894 & 86.0133 \\
\hline
\end{tabular}

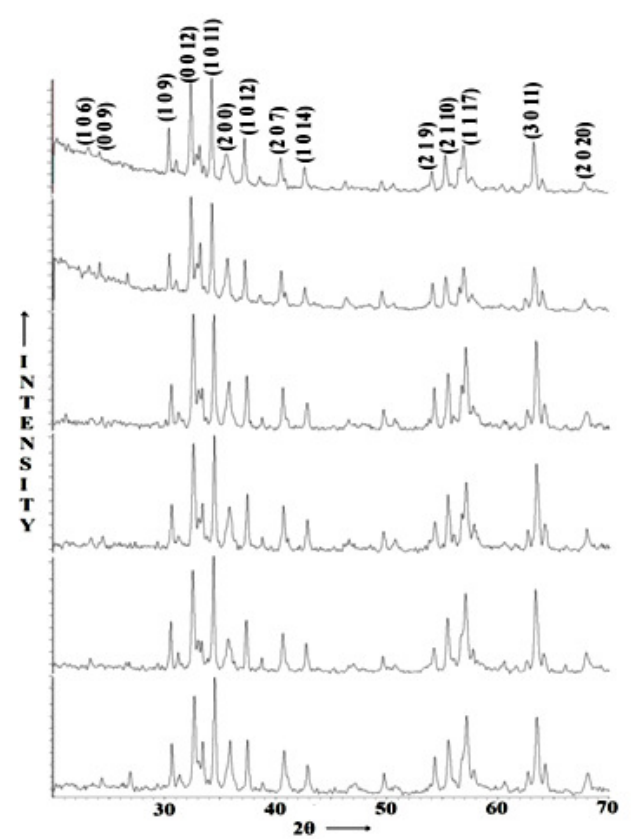

Figure. 1: $\mathrm{XRD}$ of $\mathrm{CaSr}_{2}(\mathrm{MnZn})_{\mathrm{x} / 2} \mathrm{Fe}_{16-\mathrm{x}} \mathrm{O}_{27}$ compound.

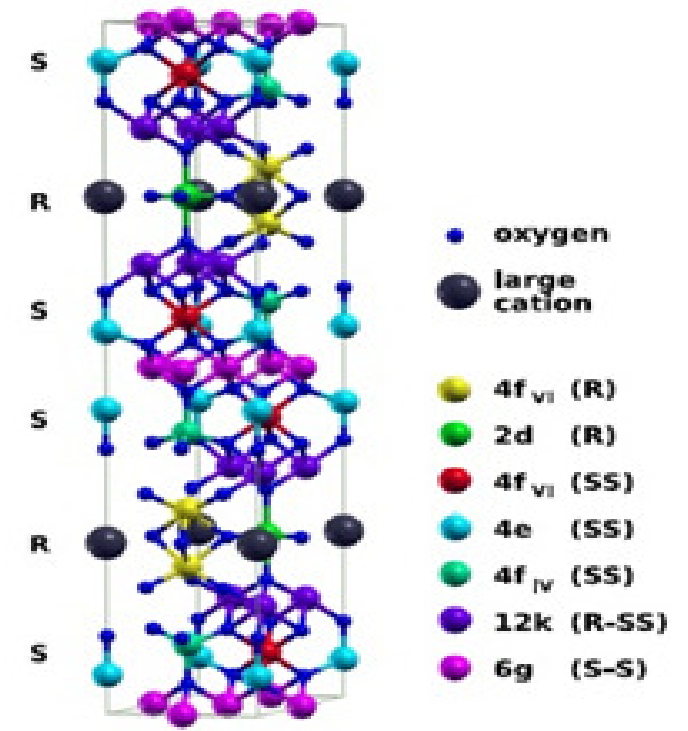

Figure. 2: Unit cell of W-type hexaferrite.
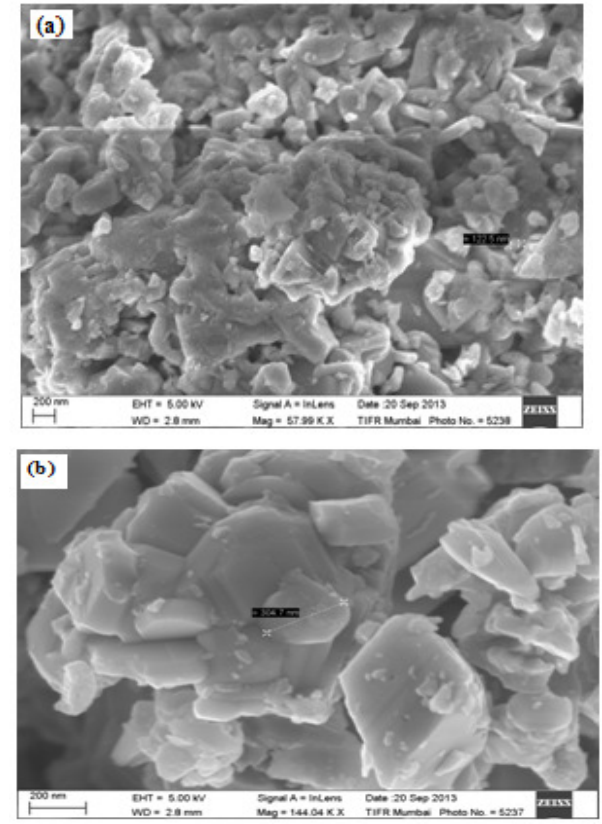

Figure. $3 \quad(\mathbf{a}, \mathbf{b}): \quad$ SEM images of $\mathrm{CaSr}_{2}(\mathrm{MnZn})_{\mathrm{x} / 2} \mathrm{Fe}_{16-\mathrm{x}} \mathrm{O}_{27}(\mathrm{x}=0.2 \& 0.6)$ ferrite synthesized at $1000^{\circ} \mathrm{C}$.

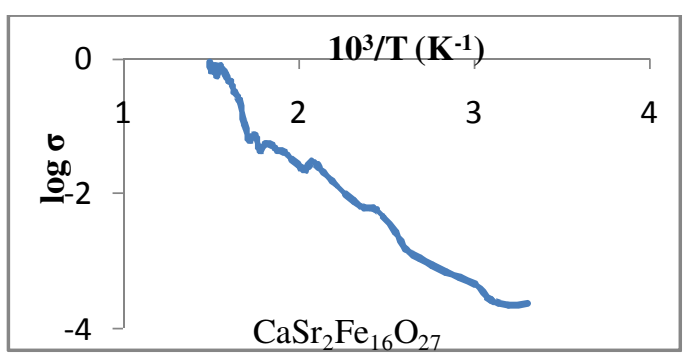

Figure.4a

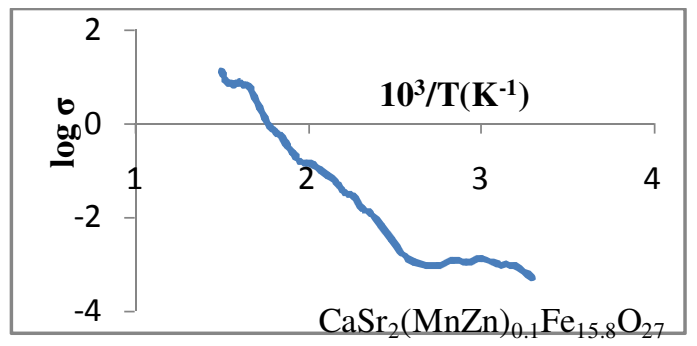

Figure.4b 


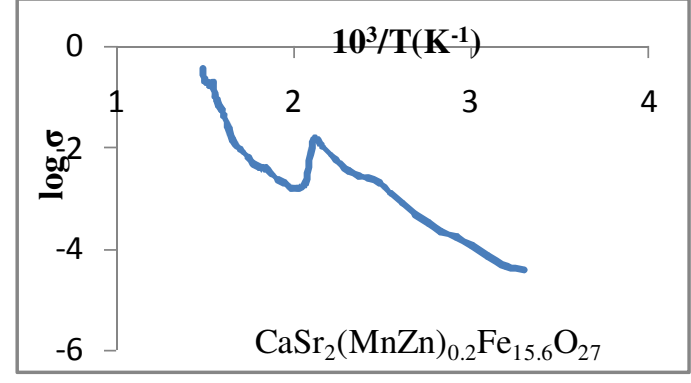

Figure.4c

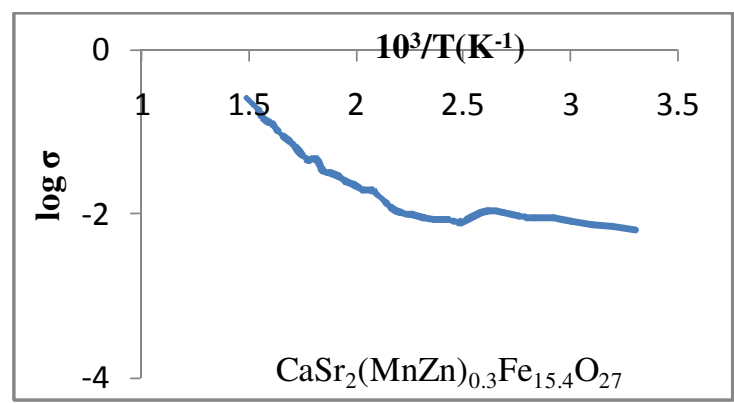

Figure. 4d

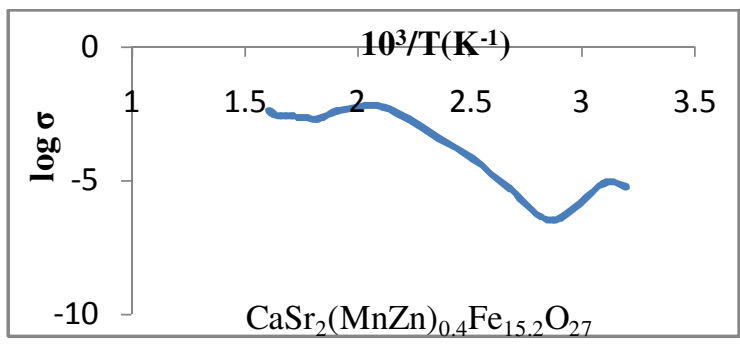

Figure. 4e

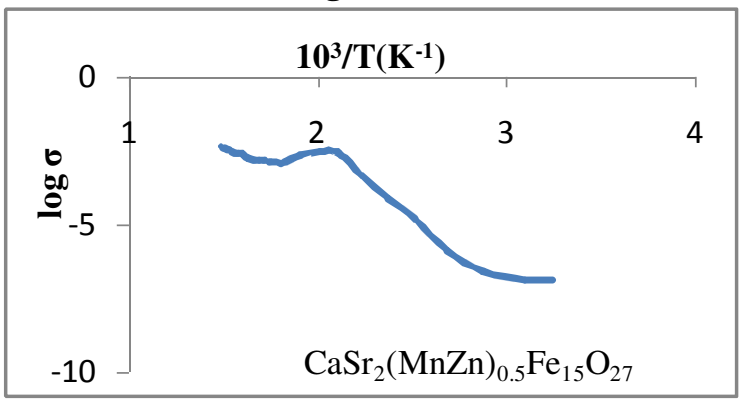

Figure. $4 f$

Figure. 4(a, b, c, d, e, f): Plot of log $\sigma$ vs inverse temperature of $\mathrm{CaSr}_{2}(\mathrm{MnZn})_{\mathrm{x} / 2} \mathrm{Fe}_{16-\mathrm{x}} \mathrm{O}_{27}$ compounds.

\section{References:}

[1] Smit J and Wijn H P J 1959 Ferrites (Eindhoven: Philips Technical Library)

[2] Asti G, Bolzoni F, Licci F and Canali M 1978 IEEE Trans. Magn. 14, 883-5

[3] Albanese G, Calabrese E, Deriu A and Licci F 1986 Hyperfine Interact 28, 487-9

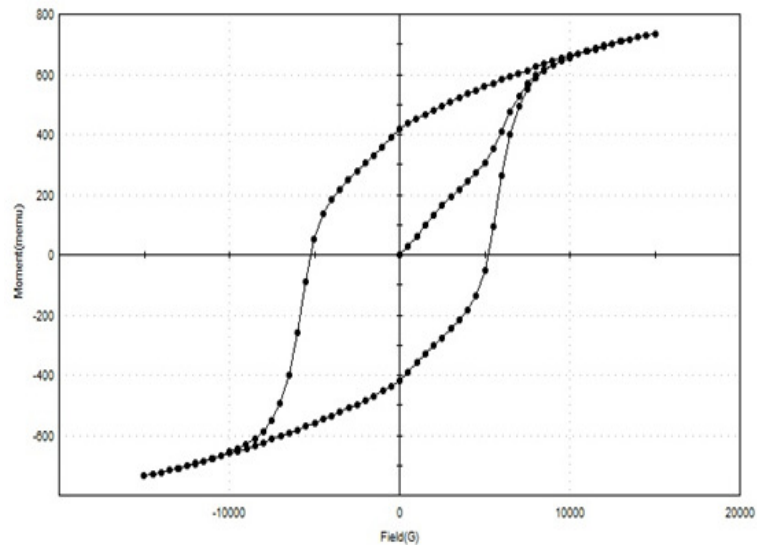

(a)

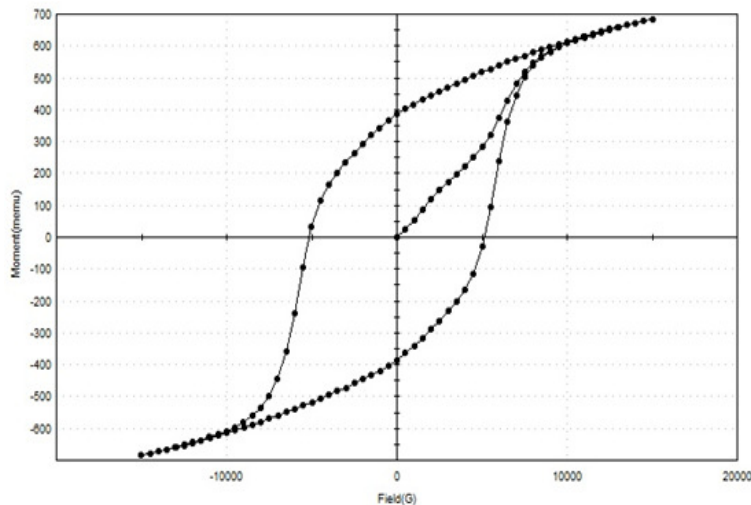

(b)

Figure. 5(a, b): VSM of $\mathrm{CaSr}_{2}(\mathrm{MnZn})_{\mathrm{x} / 2} \mathrm{Fe}_{16-\mathrm{x}} \mathrm{O}_{27}$ for $\mathrm{x}=0.2 \& 0.6$ compounds.

\section{Conclusion:}

W-type hexagonal calcium hexaferrite have been synthesized by chemical co-precipitation method using nitrates. The obtained products exhibit well crystalline phase of CaSr2(MnZn)x/2Fe16$\mathrm{xO} 27$ typical hexagonal structure. The magnetic measurement for the calcined W-type hexaferrite was observed and the values are compared with previous research reports, which exhibits enhanced hard magnetic property due to the reduced particle size. The electrical conductivity measurements observed Curie temperature in the range $473 \mathrm{~K}$ to $498 \mathrm{~K}$. The activation energies have been found in the range of 0.129 $\mathrm{eV}$ to $0.385 \mathrm{eV}$ in ferrimagnetic and $0.342 \mathrm{eV}$ to $0.838 \mathrm{eV}$ in paramagnetic region.

[4] Paoluzi A, Licci, F, Moze O, Turilli G, Deriu A, Albanese G and Calabrese E $1988 \mathrm{~J}$. Appl. Phys. 63, 5074-80

[5] Samaras D, Collomb A, Hadjivasiliou S, Achilleos C, Tsoukalas $J$, Pannetier $J$ and Rodriguez J 1989 J. Magn. Magn. Mater. 79, 193-201 
[6] Naiden E P, Maltsev V I and Ryabtsev G I 1990 Phys. Status Solidi A 120, 209-20

[7] Naiden E P and Ryabtsev G I 1990 Russ. Phys. J. 33, 318-21.

[8] Sürig C, Hempel $\mathbf{K} A$, Müller $\mathbf{R}$ and Görnert P 1995 J. Magn. Magn. Mater. 150, 270-6

[9] Turilli G and Asti G $1996 \mathrm{~J}$. Magn. Magn. Mater. 157-158, 371-2

[10] Naiden E P and Zhilyakov S. M 1997 Russ. Phys. J. 40, 869-74

[11] Jotania R. B., Khomane R. B., Deshpande A. S., Chauhan C. C., Kulkarni B. D. 2009, $J$ Sci. Res. I (1), 1-13

[12] Bayliss P, Erd D. C, More M. E. et al. Mineral Powder Diffraction File, JCPDC, USA , 1986.

[13] Pasko A, Mazaleyrat F, LoBue M, Loyau V Bessais L at al. J. of Phys: Conference series 303 (2011) 012045

[14] Klug H. P., Alexander L. E., $X$-Ray Diffraction Procedures for Polycrystalline and Amorphous Materials, Wiley, New York, 1967.

[15] Che S., Wang J. and Chen Q., Journal of Physics: Condensed Matter, 15, 335 (2003).

[16] Islam M. U., Ahmad I. Abbas T. Proceedings of the sixth International Symposium on Advanced Materials (1999), 155-p.

[17] Lide D. R. CRC Handbook of Chemistry and Physics (76th ed.) London. CRC Press 1995.
[18] Heck C. (Ed.), Magnetic Matrials and Their Applications, London Butterworth and Co. Ltd. 1974.

[19] Abbas T., Khan Y. Ahmad M. et al. Solid State Communications, 1992, 82, 701-p

[20] In Snelling E. C. (Ed.) Soft Ferrites, Properties and Applications (2 ${ }^{\text {nd }}$ ed.) London, Butter Worth and Co. Ltd. 1988.

[21] Abdullah M. H. an Ahmad S. H. SainsMalaysiana, 1993, 22, 1-p.

[22] Heneda K., Kojima H., Physica Status Solidi (A). 1971. 6. 256p.

[23] Heneda K., Kojima H , J. Appl. Phys 44, (1973), 3760.

[24] Dho J., Lee E. K., Park J. Y., and Hur N. H., J. Magn. Magn. Mater, 285, (2005), 164.

[25] Lu Y. F. and Song W. D., Appl Phys. Lett. 76, (2000), 490.

[26] Ren P., Guan J. G. and Cheng X. D., Mater. Chem. Phys. 98, (2006), 90.

[27] Mendoza-Suarez G., Matutes-Aquino J. A., Escalante-Garcia J. I., Mancha-Molinar H., Rios-Jara D. and Johal K. K., J. Magn. Magn. Mater. 223 (2001), 55.

[28] Janasi S. R., Emura M., Landgraf F. J. G. and Rodrigues D., J. Magn. Magn. Mater., 238 (2002), 168.

[29] Rashad M. M. and Ibrahim I. A., J. Magn. Magn. Mater. 323 (2011), 2158-2164. 